\title{
IMPLEMENTASI SISTEM PENGOLAHAN PENILAIAN DATA SISWA SMP NEGERI 1 SEPATAN TIMUR
}

\author{
Euis Nurninawati ${ }^{1}$, Ayu Wulandari ${ }^{2}$ \\ Program Studi Teknik Informatika Universitas Raharja Tangerang ${ }^{1,2}$ \\ Jl. Jenderal Sudirman No. 40 Cikokol Tangerang Telp. (021)-5529692 \\ Sur-el : euis.nurninawati@ raharja.info', ayu.wulandari@ raharja.info²
}

\begin{abstract}
State Junior High School 1 East Sepatan in processing data on student learning outcomes is still using the manual system, namely working with Microsoft Excel then collecting it into the new curriculum section after which it is given to the homeroom teacher in the form of paper sheets. Related to this, we need an information system of data processing value of student learning outcomes effectively and efficiently. The purpose of this study is to develop a websitebased student data assessment processing system. Step in this research is data collection, data analysis, system design, system development and testing. This research produces an information system created using the PHP programming language and MySQL as the database. From the research results, it can be concluded that a website-based assessment system can be developed to assist teachers in the assessment process and provide information on the value of student studies. With access to information provided to students and student guardians can help and monitor students or their children, then the application of student scores at State Junior High School 1 East Sepatan, Tangerang Regency is very necessary to improve the quality of good assessment services for students.
\end{abstract}

Keywords : System, Assessment, Website.

\begin{abstract}
Abstrak : SMP Negeri 1 Sepatan Timur dalam mengolah data nilai hasil belajar siswa masih menggunakan sistem manual yaitu mengerjakan dengan Microsoft excel kemudian dikumpulkan ke bagian kurikulum baru setelahnya diberikan kepada wali kelas dalam bentuk lembaran kertas. Berdasarkan hal tersebut diperlukan suatu sistem informasi pengolahan data nilai hasil belajar siswa secara efektif dan efisien. Tujuan dari penelitian ini adalah untuk mengembangkan sistem pengolahan penilaian data siswa berbasis website. Tahapan dalam penelitian ini dimulai dari pengumpulan data, analisi data, perancangan sistem, pengembangan dan pengujian sistem. Penelitian ini menghasilkan sebuah sistem informasi yang dibuat menggunakan bahasa pemrograman PHP dan MySQL sebagai databasenya. Dari hasil penelitian dapat disimpulkan bahwa sistem penilaian berbasis website dapat dikembangkan untuk membantu guru dalam proses penilaian dan memberikan informasi nilai hasil studi siswa. Dengan akses informasi yang diberikan kepada siswa dan wali murid dapat membantu dan memantau siswa.
\end{abstract}

Kata Kunci: Sistem, Penilaian, Website.

\section{PENDAHULUAN}

Perkembangan dunia pendidikan yang begitu pesat, system pengolahan nilai siswa di sekolah adalah hal yang sangat penting dilakukan untuk memasukan nilai siswa yang ada pada sekolah tersebut. Ketepatan, keakuratan, dan kecepatan dalam penginputan merupakan faktor utama dalam mendapatkan hasil yang tepat, untuk suatu fasilitas atau sarana yang sangat dibutuhkan dalam menunjang dan membantu melaksanakan pengolahan nilai yang tepat. Dibutuhkan ketersedian alat-alat yang menunjang kegiatan tersebut salah satunya adalah komputer. Pendidikan dan khususnya dalam bidang pengolahan nilai. Dengan adanya komputer, segala urusan pengolahan nilai yang biasanya harus dilakukan secara manual dapat mempermudah dengan menggunakan komputer. Dalam proses pengolahan penilaian data siswa 
yang sedang berjalan saat ini di SMP Negeri 1 Sepatan Timur merupakan salah satu sekolah menengah pertama, aktivitas yang dilakukan di SMP Negeri 1 Sepatan Timur meliputi kegiatan belajar mengajar, ekstrakurikuler dan kegiatan pendukung lainnya. Termasuk hasil belajar siswa seperti UTS, UAS dan nilai kognitif yang akan disampaikan melalui raport untuk setiap semesternya.

Terdapat sistem pengolahan nilai hasil belajar siswa yang berjalan di SMP Negeri 1 Sepatan Timur belum efektif, karena proses pengolahan nilai hasil belajar siswa masih menggunakan sistem manual. Ini merupakan permasalahan yang dihadapi para guru dalam pengolahan nilai siswa pada SMP Negeri 1 Sepatan Timur. Bagaimana cara merancang dan membangun sistem pengolahan nilai siswa pada SMP Negeri 1 Sepatan timur agar lebih cepat dan efisien?. Tujuan di dalam proses operasional penggunaan sistem pengolahan penilaian siswa. Agar fungsi dari hasil pemanfaatan ini mendapatkan informasi yang diinginkan sesuai ketentuan SMP Negeri 1 Sepatan Timur. Sehingga manfaat dari sistem ini dapat memberikan masukan untuk merancang sebuah sistem pengolahan nilai, memberikan konstribusi positif khususnya bagi SMP Negeri 1 Sepatan Timur dalam membantu pengolahan nilai hasil belajar siswa secara efektif dan efisien, dapat mempermudah proses kegiatan pengolahan nilai secara terkomputerisasi dan memberikan kemudahan dalam melihat nilai kognitif atau nilai kompetensi.

Metode untuk mendapatkan data dengan jalan pengamatan dan untuk mencari sumber informasi dengan melakukan evaluasi terhadap masalah yang ada dan melaksanakan catatan secara sistematis terhadap unsur-unsur yang diteliti, yaitu mempelajari prosedur informasi mengenai sistem pengolahan penilaian siswa pada SMP Negeri 1 Sepatan Timur. Karena dengan adanya kendala covid-19 penulis hanya melakukan obeservasi menggunakan chatting pribadi atau videocall. Metode perancangan berorientasi objek dengan metode perancangan sistem memakai UML (Unified Modeling Language) sebagai modeling tools yaitu dengan Use Case Diagram, Activity Diagram, Sequence Diagram dan Class Diagram. Bahasa pemrogramannya PHP, database servernya memakai MySQL, Sublime Text untuk listing program (coding). Metode untuk pengujian perangkat lunak yaitu black-box testing yang berfokus pada spesifikasi fungsional pada perangkat lunak, tester dapat mendefinisikan kumpulan pengetesan pada spesifikasi program.

\section{METODOLOGI PENELITIAN}

\subsection{Konsep Dasar Sistem}

Suatu sistem tidak berada dalam lingkungan yang kosong, tetapi sebuah sistem berada dan berfungsi di dalam lingkungan yang berisi sistem lainnya. Suatu sistem terdiri dari sejumlah komponen yang saling berinteraksi, bekerja sama membentuk suatu kesatuan. Apabila suatu sistem merupakan salah satu dari komponen sistem lain yang lebih besar, maka akan disebut dengan sub sistem sedangkan sistem yang lebih besar tersebut sering disebut supra sistem. Suatu sistem yang melakukan perubahan dari masukan untuk menjadi keluaran yang diinginkan. Sistem merupakan suatu bentuk 
integrasi antara satu komponen dengan komponen lain karena sistem memiliki sasaran yang berbeda untuk setiap kasus yang terjadi yang ada di dalam sistem tersebut. [1].

\section{$2.2 \quad$ Website}

Web adalah sistem dengan informasi yang dijadikan dalam bentuk teks, gambar, suara dan lainnya yang tersimpan dalam sebuah server web internet yang disajikan dalam bentuk hypertext $[2]$.

\section{$2.3 \quad$ PHP}

PHP adalah singkatan dari Hypertext Preprocessor yang merupakan salah satu bahasa skrip yang dirancang untuk membangun aplikasi web. Ketika dipanggil dari web browser, program yang ditulis dengan PHP akan diparsing di dalam web server oleh interpreter PHP dan diterjemahkan ke dalam dokumen HTML, yang selanjutnya akan ditampilkan kembali ke web browse[3].

\subsection{XAMPP}

XAMPP adalah kompilasi software yang membungkus Apache HTTP Server, MySQL, PHP dan Perl. Dengan menggunakan XAMPP, instalasi paket software yang dibutuhkan untuk proses pengmbangan web (Apache HTTP Server, $M y S Q L$ dan PHP) dapat dilakukan dengan sangat mudah, tanpa harus dilakukan secara terpisah (sendiri-sendiri)[4].

\subsection{Unified Model Language (UML)}

UML (Unified Modelling Language) adalah himpunan struktur dan teknik untuk permodelan desain program berorientasi objek
(OOP) serta aplikasinya. UML adalah metodologi untuk mengembangkan sistem OOP dan seperangkat tool untuk mendukung pengembangan sistem tersebut [5]. Jenis UML yang digunakan oleh peneliti pada pengembangan aplikasi ini adalah Use Case Diagram, Activity Diagram, dan Class Diagram.

\subsection{Entity Relationship Diagram (ERD)}

Entity Relationship Diagram merupakan bentuk paling awal dalam menjelaskan hubungan antar data dalam basis data berdasarkan objekobjek dasar data yang mempunyai hubungan antar relasi. ERD dikembangkan berdasarkan teori himpunan dalam bidang metematika [6].

\subsection{Database}

Database adalah kumpulan data atau segala sesuatu yang berhubungan dengan data. Database merupakan salah satu komponen yang sangat penting dalam sistem informasi, karena merupakan basis sistem dalam menyediakan informasi bagi para pemakai [1].

\subsection{MySQL}

MySQL merupakan sebuah perangkat lunak atau software sistem manajemen basis data SQL atau DBMS multi thread dan multi user. MySQL bersifat open source dan free pada berbagai platform. Saat ini MySQL adalah salah satu jenis database server yang sangat terkenal dan banyak digunakan untuk membangun aplikasi web yang menggunakan database sebagai sumber dan pengolahan datanya [7]. Perintah SQL dibagi dalam 2 kategori besar sesuai fungsinya, yaitu: 
1. DDL - Data Definition Language merupakan kumpulan perintah SQL yang digunakan untuk membuat, mengubah dan menghapus struktur dan definisi data dari objek-objek database.

2. DML - Data Manipulation Language merupakan kumpulan perintah SQL yang digunakan untuk proses pengolahan isi data di dalam table seperti memasukan, merubah dan menghapus isi data - dan tidak terkait dengan perubahan struktur dan definisi tipe data dari objek database.

\section{HASIL DAN PEMBAHASAN}

Urutan proses dari awal sampai akhir yang terjadi dalam sistem pengolahan data nilai siswa SMP Negeri 1 Sepatan Timur:

1. Guru memiliki nilai

Pada proses ini guru memberikan data nilai kepada wali kelas

2. Wali kelas

Pada proses ini wali kelas menginput data siswa, data pelajaran, dan data nilai siswa.

3. Siswa

Pada proses ini siswa bisa menerima raport berbasis website.

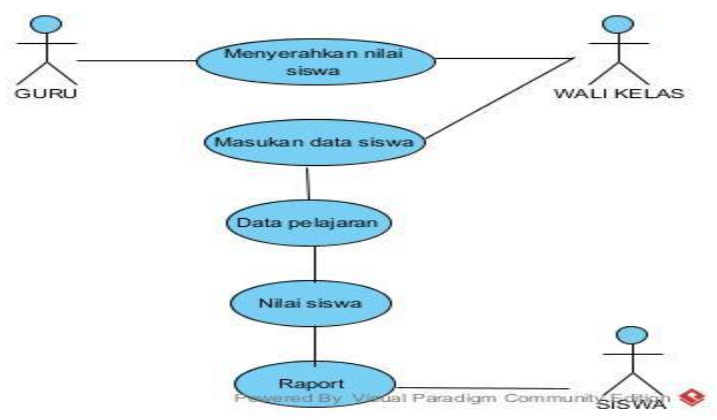

Gambar 1. Use Case Diagram Pengolahan Data Nilai

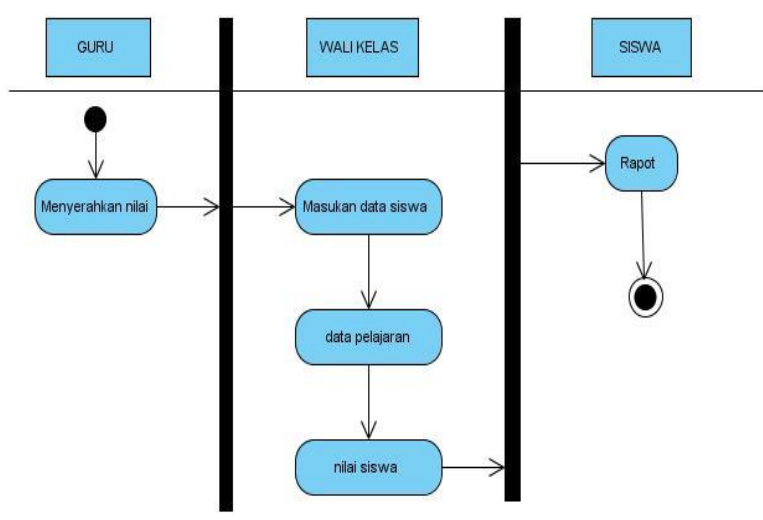

Gambar 2. Activity Diagram Pengolahan Nilai

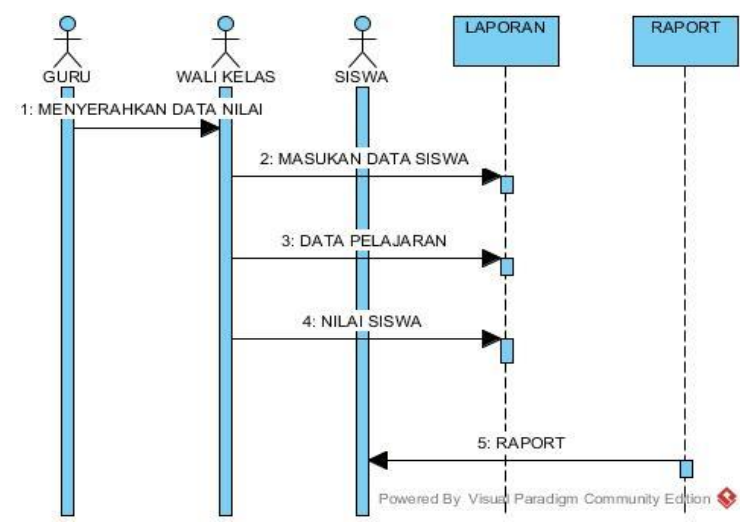

Gambar 3. Squence Diagram Pengolahan Data Nilai

Dapat dijelaskan pada gambar di atas bahwa guru yang mempunyai sebuah nilai siwa/siswi, guru tersebut menyerahkan nilai ke wali kelas kemudian si wali kelas ini melakukan pengolahan data dengan diolahnya data nilai tersebut akan menjadi mudah bagi para guru dan dapat melihat hasil dari nilai yang sudah diolah dengan baik dan diberikan kepada siswa.

Suatu sistem pada dasarnya merupakan suatu susunan teratur dari sekumpulan kegiatankegiatan yang saling berhubungan antara satu dengan yang lainnya, dan prosedur-prosedur yang dilaksanakan saling berkaiatan sehingga kemudahan untuk melakukan kegiatan. Perkembangan suatu sistem sering kali 
dipengaruhi oleh perubahan kondisi yang dihadapi. Pengujian sistem dilakukan untuk menggambarkan sebuah sistem yang berjalan. Tahapan ini berisikan hasil eksekusi program dan penjelasan program yang dibuat untuk mendukung sistem yang dirancang.

Tabel 1. Perbedaan Prosedur Antara Sistem yang Berjalan dan Sistem Usulan

\begin{tabular}{|c|c|c|}
\hline No & $\begin{array}{l}\text { Sistem Yang } \\
\text { Berjalan }\end{array}$ & $\begin{array}{l}\text { Sistem yang } \\
\text { Diusulkan }\end{array}$ \\
\hline 1 & $\begin{array}{l}\text { Sistem yang sedang } \\
\text { berjalan saat ini } \\
\text { masih belum } \\
\text { optimal karena } \\
\text { banyaknya } \\
\text { kesalahan pada saat } \\
\text { pendataan nilai } \\
\text { dengan cara } \\
\text { manual. }\end{array}$ & $\begin{array}{l}\text { Dengan adanya } \\
\text { sistem yang dibuat } \\
\text { bisa mempermudah } \\
\text { guru dalam } \\
\text { pencatatan nilai dan } \\
\text { absensi secara } \\
\text { terkomputerisasi, } \\
\text { sehingga jarang } \\
\text { terjadi kesalahan } \\
\text { pendataan. }\end{array}$ \\
\hline 2 & $\begin{array}{l}\text { Akses terbatas } \\
\text { karena hanya } \\
\text { tersimpan pada } \\
\text { staff admin yang } \\
\text { mengerjakan } \\
\text { laporan }\end{array}$ & $\begin{array}{l}\text { Akses sistem } \\
\text { diberikan ke beberapa } \\
\text { user yang } \\
\text { berkepentingan } \\
\text { sehingga pengecekan } \\
\text { hasil kerja menjadi } \\
\text { lebih mudah. }\end{array}$ \\
\hline 3 & $\begin{array}{l}\text { Dibutuhkan waktu } \\
\text { yang cukup lama } \\
\text { dalam } \\
\text { menghasilkan } \\
\text { laporan pencatatan } \\
\text { nilai karena } \\
\text { dilakukan secara } \\
\text { manual dari proses } \\
\text { ke proses lainnya. }\end{array}$ & $\begin{array}{l}\text { Pembuatan laporan } \\
\text { lebih efektif karena } \\
\text { data yang dihasilkan } \\
\text { telah terintegrasi dari } \\
\text { sistem }\end{array}$ \\
\hline 4 & $\begin{array}{l}\text { Masih } \\
\text { menggunakan } \\
\text { kertas dan semi } \\
\text { komputerisasi } \\
\text { untuk pencatatan } \\
\text { sehingga banyak } \\
\text { menggunakan } \\
\text { kertas dan terjadi } \\
\text { kerusakan pada } \\
\text { kertas sebelum } \\
\text { diinput }\end{array}$ & $\begin{array}{l}\text { Semua laporan tidak } \\
\text { akan hilang karena } \\
\text { tersimpan aman } \\
\text { dalam database. }\end{array}$ \\
\hline
\end{tabular}

Dalam membangun basis data fisik yang ditempatkan dalam memori sekunder (disk) dengan bantuan manajamen basis data atau DBMS (Database Management System) yang dipilih. Tahapan implementasi basis data dapat dilakukan dengan transformasi dari model data yang telah selesai dibuat ke skema/struktur basis data sesuai DBMS yang dipilih. Atribut-atribut yang melekat pada masing-masing himpunan entitas dan himpunan relasi akan dinyatakan sebagai field-field dari tabel-tabel yang sesuai.

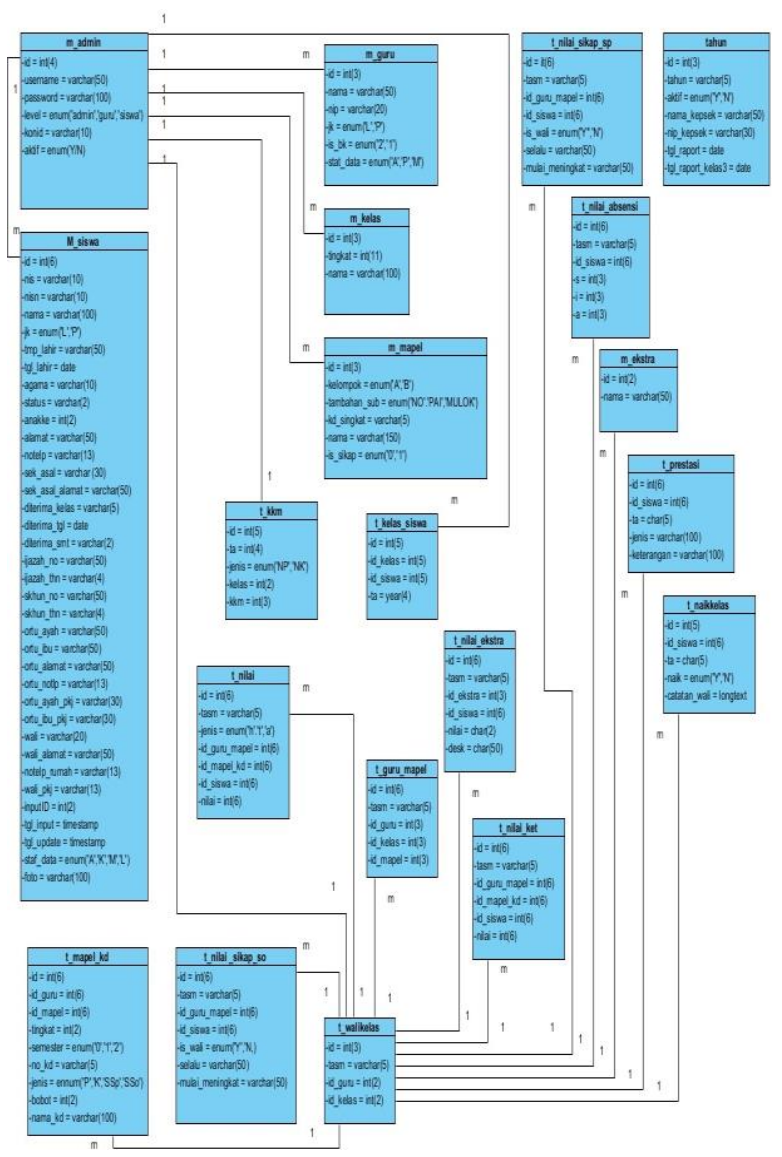

Gambar 4. Rancangan Basis Data

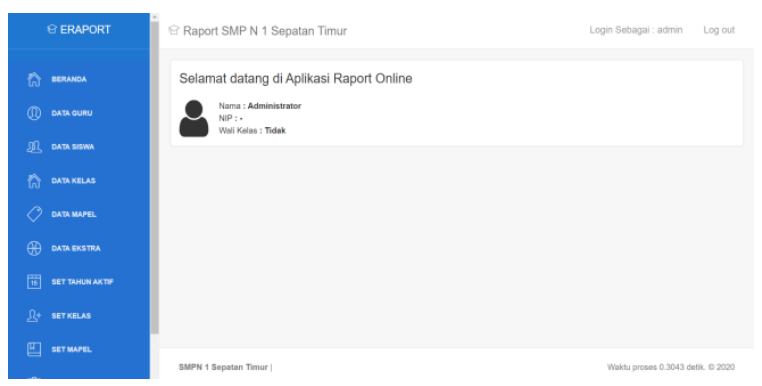




\section{Gambar 5. Halaman Dasboard Admin}

Terdapat daftar admin dan menu user admin, Di bagian kanan terdapat profile user, menu guru untuk melihat dan menambahkan daftar guru, menu siswa untuk menambahkan jumlah siswa dan nilai siswa, dan ada juga menu wali walikelas.

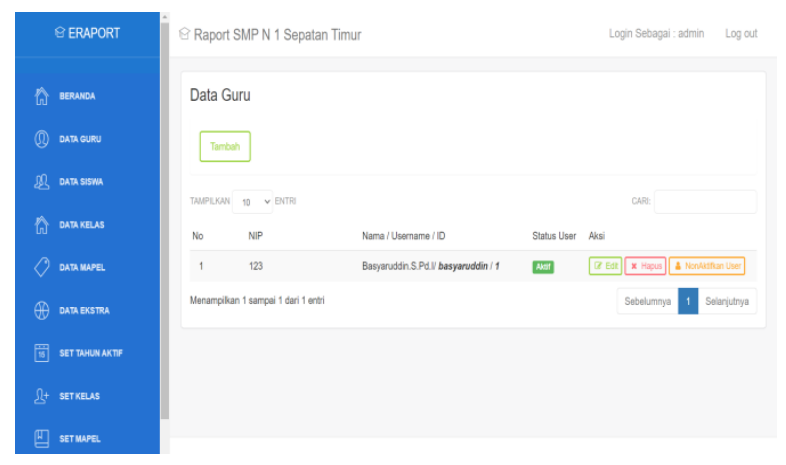

\section{Gambar 6. Halaman Data Guru}

Terdapat daftar guru atau jumlah user guru, jika ingin menambahkan user guru klik tombol tambah warna hijau yang berada pada atas kanan layar lalu mengisi data-data untuk guru.

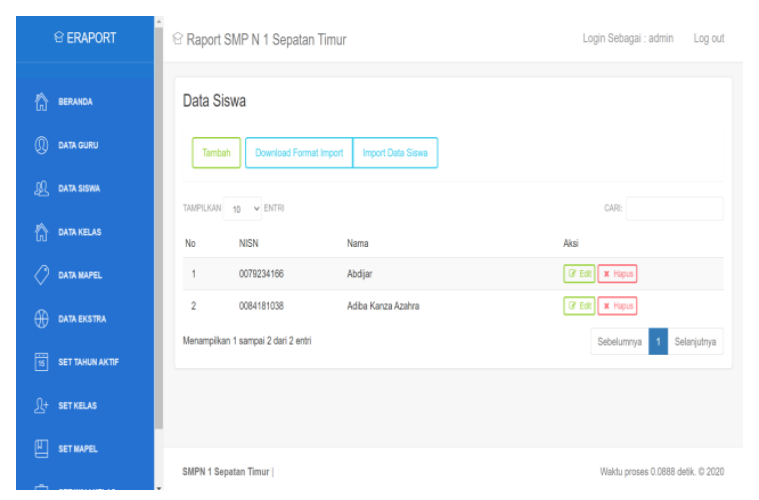

Gambar 7. Halaman Data Siswa

Untuk menampilkan menu data siswa, menu tambah siswa, menu import data siswa dan menampilkan daftar-daftar siswa.

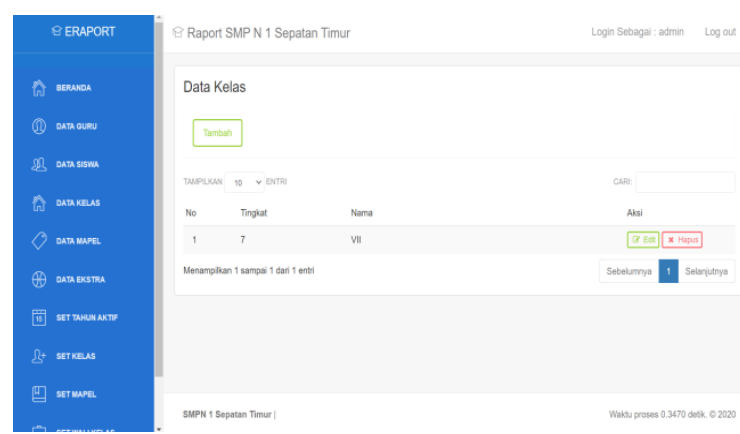

Gambar 8. Halaman Data Kelas

Ini adalah tampilan halaman data kelas yang berisi data kelas-kelas siswa

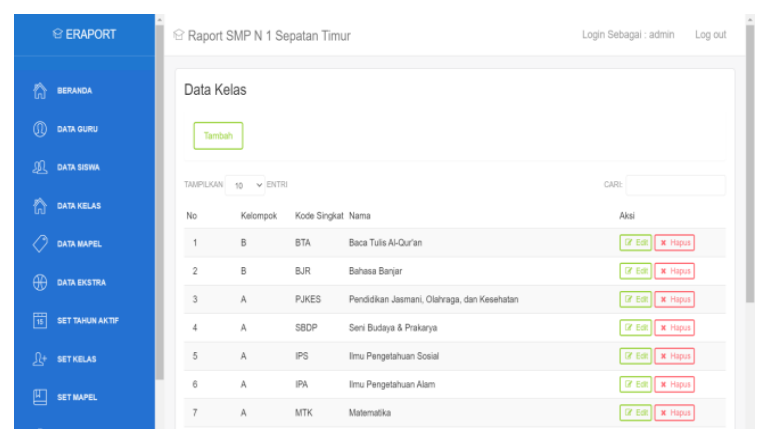

Gambar 9. Halaman Data Mapel

Halaman data mapel (mata pelajaran) yang berisi data mata pelajaran dan kelompok mapel (mata pelajaran).

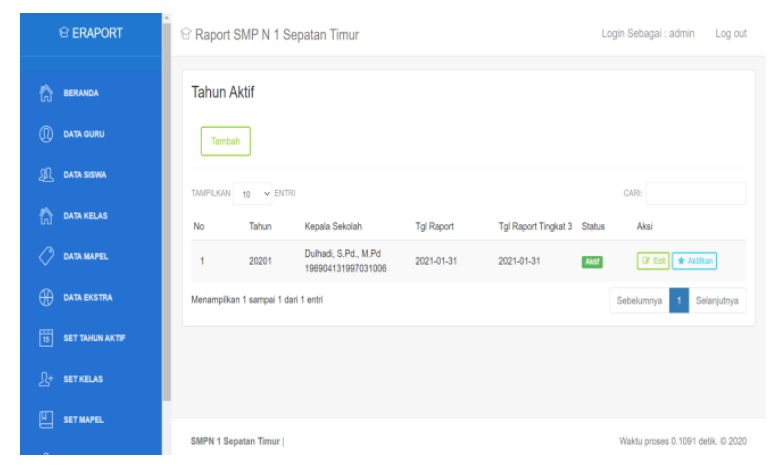

\section{Gambar 10. Halaman Tahun Aktif}

Halaman tahun aktif yang berisi tahun aktif kepala sekolah.

Metode uji dapat diterapkan pada semua tingkat pengujian perangkat lunak: unit, integrasi, fungsional, sistem dan penerimaan. Ini biasanya terdiri dari kebanyakan jika tidak semua 
pengujian pada tingkat yang lebih tinggi, tetapi

juga bisa mendominasi unit testing juga.

Tabel 2. Black Box Testing

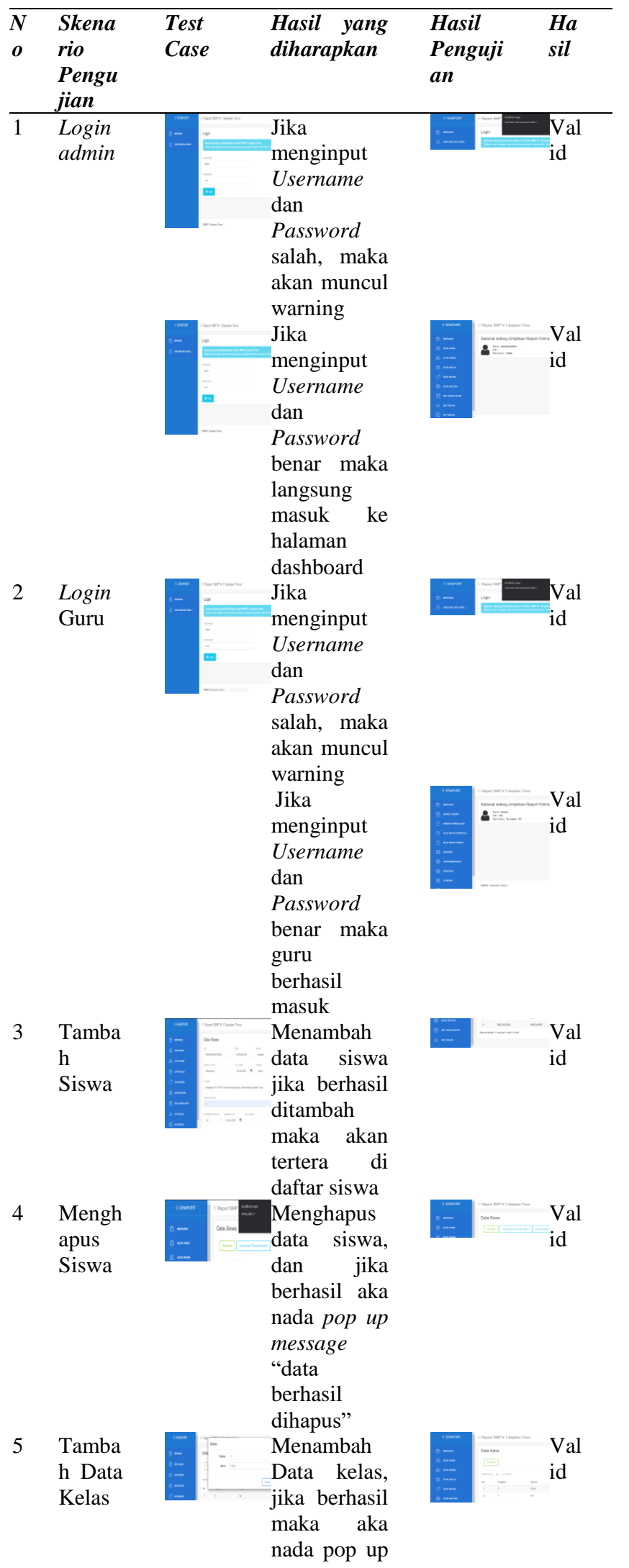

"Data

Berhasil

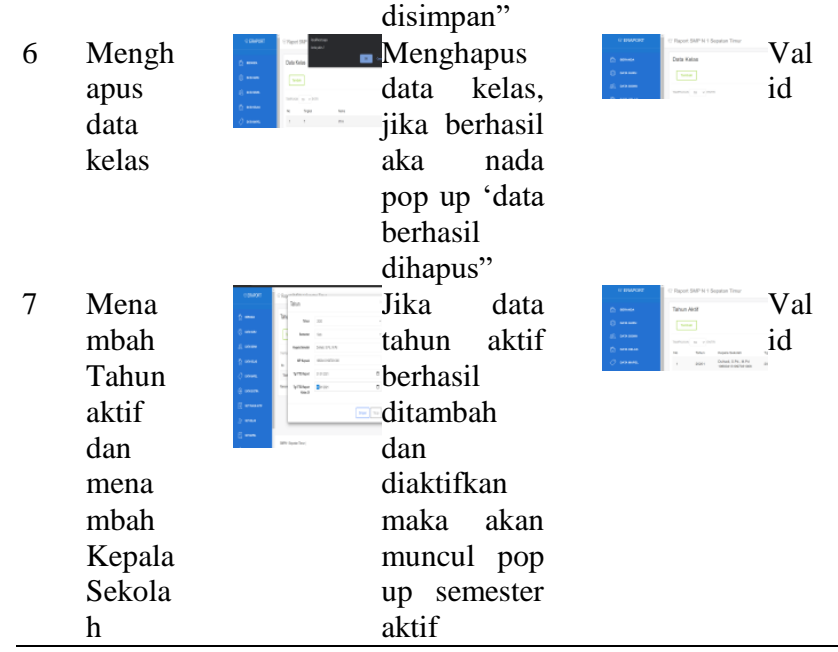

Berdasarkan hasil uji coba, dilakukan dengan cara memberikan sejumlah input pada program. Input tersebut kemudian di proses sesuai dengan kebutuhan fungsionalnya untuk melihat apakah program aplikasi dapat menghasilkan output yang sesuai dengan yang diinginkan dan sesuai pula dengan fungsi dasar dari program tersebut. Dalam melakukan penelitian ini tentu memerlukan proses dan kegiatan yang banyak memakan waktu dalam penyelesaiannya. Hasil penelitian tersebut menemukan item kategori pengolahan nilai raport siswa guna lebih terarah dan berjalan dengan baik, dan memberikan kemudahan dalam melihat nilai kognitif atau nilai kompetensi.

\section{KESIMPULAN}

Implementasi Sistem Penilaian Siswa SMP Negeri 1 Sepatan Timur, dapat ditarik kesimpulan sebagai berikut:

1. Sistem penilaian Siswa yang berjalan saat ini di SMP Negeri 1 Sepatan Timur belum sepenuhnya terkomputerisasi. Mekanisme kerjanya adalah menerima berkas penilaian 
siswa dari setiap guru mata pelajaran setelah itu dicatat dalam buku kumpulan nilai dan menyalinnya kembali dalam satu buku yang disebut dengan raport. Setelah penyalinan tersebut raport disimpan dan dibagikan kepada setiap wali murid pada waktu penyerahan raport berlangsung. Dalam jangka waktu yang ditentukan oleh pihak sekolah, siswa diminta untuk mengembalikan raport tersebut kepada guru wali setiap kelas.

2. Kendala dalam penilaian siswa yang berjalan saat ini di SMP Negeri 1 Sepatan Timur adalah adanya siswa dan masing-masing mempunyai nilai yang berbeda-beda, sehingga membutuhkan waktu yang sangat lama dalam pengerjaannya. Oleh karena itu perekapan nilai siswa disimpan secara tertulis oleh para guru.

3. Dalam perancang sistem informasi penilaian siswa yang diusulkan, menggunakan orientasi objek (Unifiled Modeling Language), Pengimplementasinya menggunakan PHP serta database MySQL serta pengujiannya menggunakan Black Box Testing sedangkan tampilan menu programnya terdiri dari menu login, data (siswa, guru, dan admin), nilai ekstra (Tugas1, Tugas2), raport (UTS dan UAS) dan transkip nilai.

Penerapan sistem yang berjalan, penulis ingin mengemukakan saran agar sistem bisa berjalan dengan lebih baik. Didalam sistem yang baru ini sudah berjalan, perlu diperhatikan dan dilakukan evaluasi secara berkala terhadap sistem, untuk selanjutnya diadakan perbaikan sesuai perubahan dan perkembangan pada SMP Negeri 1 Sepatan Timur.

\section{DAFTAR PUSTAKA}

[1] Sutabri, Tata., "Sistem Informasi Manajemen”. CV ANDI OFFSET : Yogyakarta. 2016.

[2] Maimunah, Dini Luigi dan Ade Ferdiansyah., "Rancang Bangun Sistem Pelayanan Data Pelanggan (Xibar) Berbasis Online". Jurnal Seminar Nasional Teknologi Informasi dan Multimedia. ISSN : 2302- 3805. 2017.

[3] Budi Raharjo, Imam Heryanto, and E. Rosdiana, "Modul Pemrograman Web HTML, PHP \& MYSQL". Bandung: Modula, 2014.

[4] Budi Raharjo., "Belajar Otodidak Framework CodeIgniter". Informatika Bandung, 2015.

[5] Yusuf, Muhammad, Ary Budi Warsito, Moh Iqbal Awi Makaram., "Perancangan SIS+ Menggunakan Metode YII Framework Pada Perguruan Tinggi Raharja”. Jurnal CCIT Vol. 8 No. 2 Januari 2015.

[6] M. Shalahuddin, Rosa A.S., Rekayasa Perangkat Lunak. Bandung: Informatika, 2014.

[7] B. Sidik. "Framework Codeigniter". Bandung: Informatika, 2012. 